\title{
Chain-Growth Polymerization for the Synthesis of Polyfluorene via Suzuki-Miyaura Coupling Reaction from an Externally
}

\author{
Added Initiator Unit
}

\author{
Akihiro Yokoyama, Hirofumi Suzuki, Yasuhiro Kubota, Kazuei Ohuchi, \\ Hideyuki Higashimura, ${ }^{*}$ and Tsutomu Yokozawa*
}

\section{Supporting Information}

\section{General.}

Measurements. ${ }^{1} \mathrm{H}$ and ${ }^{13} \mathrm{C}$ NMR spectra were obtained on Bruker Avance 600 or Varian Inova 300 spectrometers, and internal standards for ${ }^{1} \mathrm{H}$ and ${ }^{13} \mathrm{C}$ NMR were tetramethylsilane $(0.00 \mathrm{ppm})$ and $\mathrm{CDCl}_{3}$ (77.00 ppm), respectively. Conversion of monomer was determined by high performance liquid chromatography (HPLC) performed on a Shimadzu SCL-10AVP instrument with a Kaseisorb LC-ODS column $(4.6 \mathrm{~mm} \times 10 \mathrm{~cm})$ and a Shimadzu SPD-M10AVP detector $(254$ or $210 \mathrm{~nm})$ using $\mathrm{CH}_{3} \mathrm{CN} /$ tetrahydrofuran (THF) as an eluent $(1 \mathrm{~mL} / \mathrm{min})$. A LC mass spectrum was recorded on a $\mathrm{HP}$ 1100 LCMSD with atmospheric pressure photoionization (APPI) at positive mode. MALDI-TOF mass spectra were recorded on a Bruker Reflex III in the reflectoron mode with a laser $(\lambda=337 \mathrm{~nm})$ using 1,1,4,4-tetraphenyl-1,3-butadiene as a matrix. $M_{\mathrm{n}}$ and $M_{\mathrm{w}} / M_{\mathrm{n}}$ values of polymers were measured with a TOSOH HLC-8220 gel-permeation chromatography (GPC) system with three TSK-gel SuperHM-H 
columns and a RI detector using THF as eluent $(0.50 \mathrm{~mL} / \mathrm{min})$ at $60{ }^{\circ} \mathrm{C}$, which were calibrated with polystyrene standards.

Materials. 2-(7-Bromo-9,9-dioctyl-9H-fluoren-2-yl)-4,4,5,5-tetramethyl-1,3,2-dioxaborolane (1a) was prepared in the way similar to the literature. ${ }^{1}$ 4-Bromo-2,5-dibutyloxyphenylboronic acid (1b) was prepared by the reported procedure. ${ }^{2}{ }^{1} \mathrm{Bu}_{3} \mathrm{PPd}(\mathrm{Ph}) \mathrm{Br}(\mathbf{2})$ was prepared in the reported mannner, ${ }^{3}$ as shown below. 2-Bromo-7-(4-tert-butylphenyl)-9,9-dioctylfluorene (6) was synthesized as below. Other solvents and reagents were used as commercially available grade without further purification.

Synthesis of 2. ${ }^{3}$ All operation was performed under nitrogen in a gloved box. $\mathrm{Pd}\left(\mathrm{P}^{t} \mathrm{Bu}_{3}\right)_{2}(100 \mathrm{mg}$, $0.196 \mathrm{mmol})$ and phenyl bromide $(1.02 \mathrm{~mL}, 9.8 \mathrm{mmol})$ were added to a screw-capped vial. After stirring for $2.5 \mathrm{~h}$ at $70^{\circ} \mathrm{C}$, the reaction mixture was poured into pentane $(10 \mathrm{~mL})$ at room temperature. A yellow precipitate was collected by filtration, washed five times with pentane $(3.4 \mathrm{~mL})$, and dried under reduced pressure to give 2 as a yellow powder (49 $\mathrm{mg}, 54 \%$ ). The product was stored under an argon atmosphere in a refrigerator. The structure of $\mathbf{2}$ was characterized by comparison with the reported NMR data. ${ }^{3}{ }^{1} \mathrm{H}$ NMR (300 MHz, THF- $\left.d_{8}\right): \delta 1.47(\mathrm{~d}, 27 \mathrm{H}), 6.73-6.82(\mathrm{~m}, 3 \mathrm{H}), 7.22(\mathrm{~d}, 2 \mathrm{H})$. ${ }^{31} \mathrm{P}$ NMR (121 MHz, THF- $\left.d_{8}\right): \delta 63.4$.

Synthesis of 6. In a three-neck round-bottom flask, 2,7-dibromo-9,9-dioctylfluorene (2.47 g, $4.5 \mathrm{mmol})$ and tetrakis(triphenylphosphine)palladium $(0)(130 \mathrm{mg}, 0.11 \mathrm{mmol})$ were replaced, and the flask was evacuated then filled with argon. After addition of toluene $(75 \mathrm{~mL})$ to the flask, a solution of 2-(4-tertbutylphenyl)-4,4,5,5-tetramethyl-1,3,2-dioxaborolane (1.17 g, $4.5 \mathrm{mmol}$ ) (Boron Molecular Pty Ltd) in toluene $(25 \mathrm{~mL})$ and a $2 \mathrm{~mol} / \mathrm{L}$ aqueous solution of $\mathrm{Na}_{2} \mathrm{CO}_{3}(25 \mathrm{~mL})$ were added. The mixture was stirred at $80^{\circ} \mathrm{C}$ for $24 \mathrm{~h}$, and then cooled to room temperature. The product was extracted with $\mathrm{CH}_{2} \mathrm{Cl}_{2}$, the organic layer was washed with water and dried over $\mathrm{MgSO}_{4}$, and the solvent was evaporated. After column chromatography on silica gel with hexane, 6 was obtained as a white powder $(1.18 \mathrm{~g}, 44 \%) .{ }^{1} \mathrm{H}$ NMR (300 MHz, $\left.\mathrm{CDCl}_{3}\right): \delta 0.65(\mathrm{~m}, 4 \mathrm{H}), 0.81(\mathrm{t}, 6 \mathrm{H}), 1.05-1.21(\mathrm{~m}, 20 \mathrm{H}), 1.38(\mathrm{~s}, 9 \mathrm{H}), 1.88-2.02(\mathrm{~m}$, 
4H), 7.43-7.62 (m, 9H), 7.69 (d, 1H). ${ }^{13} \mathrm{C}$ NMR (75 MHz, $\left.\mathrm{CDCl}_{3}\right): \delta$ 14.1, 22.6, 23.7, 29.1, 29.2, 29.9, $31.4,31.8,34.5,40.3,55.4,120.0,120.9,121.0,121.4,125.7,125.9,126.1,126.8,129.9,138.6,139.0$, 139.9, 140.3, 150.3, 150.9, 153.2. LCMS (APPI): $m / z$ (relative intensity) $600\left(\mathrm{M}^{+} ; 96\right), 601(39), 602$ (100), $603(38)$.

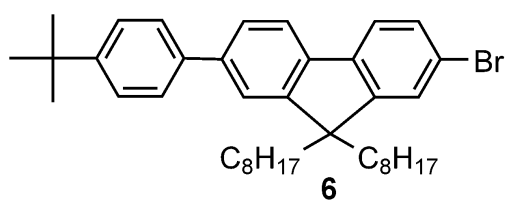

\section{Polymerization of 1 initiated by 2.}

Typical procedure. In a two-neck round-bottom flask, 1a (148 $\mathrm{mg}, 0.248 \mathrm{mmol})$ was placed and vacuum was applied, which was then cancelled with argon. THF (stabilizer free, $8 \mathrm{~mL}$ ) and $2 \mathrm{~mol} / \mathrm{L}$ aqueous solution of $\mathrm{Na}_{2} \mathrm{CO}_{3}(5 \mathrm{~mL})$ were added, and the mixture was stirred at room temperature. The polymerization was initiated by adding a solution of $2(5.8 \mathrm{mg}, 0.012 \mathrm{mmol}, 5 \mathrm{~mol} \%$ based on 1a) in THF ( $2 \mathrm{~mL}$ ). After $30 \mathrm{~min}$, the organic phase was separated and poured into a mixture of $2 \mathrm{~mol} / \mathrm{L}$ hydrochloric acid $(5 \mathrm{~mL})$ and methanol $(40 \mathrm{~mL})$ with stirring. The precipitate was collected by filtration, washed with water and methanol, and dried under reduced pressure overnight to give poly $(9,9$ dioctylfluorene) (5a) as a yellow powder (83 mg, 85\%). $M_{\mathrm{n}}=17700, M_{\mathrm{w}} / M_{\mathrm{n}}=1.33(\mathrm{GPC}) .{ }^{1} \mathrm{H}$ NMR (600 MHz, $\mathrm{CDCl}_{3}$, Figure S1): $\delta 0.82(\mathrm{~m}, 10 \mathrm{H}), 1.14(\mathrm{~m}, 20 \mathrm{H}), 2.13(\mathrm{br}, 4 \mathrm{H}), 7.68(\mathrm{~s}, 2 \mathrm{H}), 7.70(\mathrm{~d}, 2 \mathrm{H})$, $7.85(\mathrm{~d}, 2 \mathrm{H})$. The small peaks at 7.35-7.55 ppm in Figure S1 seem to be due to the phenyl group at the initiator end. ${ }^{13} \mathrm{C}$ NMR (75 MHz, $\mathrm{CDCl}_{3}$, Figure S2): $\delta$ 14.1, 22.6, 23.9, 29.3 (2C), 30.1, 31.8, 40.4, $55.4,120.0,121.5,126.2,140.0,140.5,151.8$. The small peaks at 127.2 and 128.8 ppm in Figure S2 seem to be due to the phenyl group at the initiator end. The enlarged MALDI-TOF mass spectrum of $\mathrm{Ph} / \mathrm{Br}$-ended polymer 5a with degree of polymerization (n) of 7 (Figure S3a) was in good agreement with the calculated one (Figure S3b).

Polymerization of $\mathbf{1 b}$ was carried out in a manner similar to the procedure described above using $\mathbf{1 b}$ (172 mg, $0.50 \mathrm{mmol})$, THF $(15 \mathrm{~mL}), 2 \mathrm{~mol} / \mathrm{L}$ aqueous solution of $\mathrm{Na}_{2} \mathrm{CO}_{3}(10 \mathrm{~mL})$, and a solution of 2 
(11.6 mg, $0.023 \mathrm{mmol}, 5 \mathrm{~mol} \%$ based on $\mathbf{1 b})$ in THF $(5 \mathrm{~mL})$. Polymerization for $30 \mathrm{~min}$ at room temperature followed by pouring the reaction mixture into $2 \mathrm{~mol} / \mathrm{L}$ hydrochloric acid gave the polymer 5b (90.3 mg, 82\%). $M_{\mathrm{n}}=11000, M_{\mathrm{w}} / M_{\mathrm{n}}=1.53(\mathrm{GPC}) .{ }^{1} \mathrm{H} \mathrm{NMR}\left(300 \mathrm{MHz}, \mathrm{CDCl}_{3}\right.$, Figure S4): $\delta 0.90$ $(\mathrm{t}, 6 \mathrm{H}), 1.30-1.47(\mathrm{~m}, 4 \mathrm{H}), 1.59-1.76(\mathrm{~m}, 4 \mathrm{H}), 3.93(\mathrm{t}, 4 \mathrm{H}), 7.10(\mathrm{~s}, 2 \mathrm{H})$. The small peaks at $7.33 \mathrm{ppm}$ (t), $7.43 \mathrm{ppm}(\mathrm{t})$, and $7.64 \mathrm{ppm}(\mathrm{d})$ in Figure S4 seem to be due to the phenyl group at the initiator end. ${ }^{13} \mathrm{C}$ NMR (75 MHz, $\mathrm{CDCl}_{3}$, Figure S5): $\delta 13.8,19.3,31.6,69.2,117.3,127.6,150.1$. The small peaks at 127.8 and $129.6 \mathrm{ppm}$ in Figure S5 seem to be due to the phenyl group at the initiator end.

Polymerization behavior. In order to examine the relationship between the conversion of $1 \mathrm{a}$ and the $M_{\mathrm{n}}$ of 5a, polymerization was performed similarly to the above typical procedure except for the presence of 1-phenyloctane (used as an internal standard for HPLC analysis, $86 \mathrm{mg}$ ). To analyze the conversion of the monomer 1a and $M_{\mathrm{n}}$ and $M_{\mathrm{w}} / M_{\mathrm{n}}$ values of the polymer, a small aliquot $(300 \mu \mathrm{L})$ of the organic phase of the reaction mixture was sampled at 1,2,3, and $180 \mathrm{~min}$. A half of the aliquot was poured into a mixture of $2 \mathrm{~mol} / \mathrm{L}$ hydrochloric acid and methanol, and the mixture was filtered. The filtrate was analyzed by HPLC, and the conversion of 1a was determined on the basis of 1-phenyloctane as the internal standard $(67,78,80$, and $\sim 100 \%$ for $1,2,3$, and 180 min, respectively). The other half of the aliquot was poured into a mixture of $2 \mathrm{~mol} / \mathrm{L}$ hydrochloric acid and methanol, and the mixture was concentrated by flushing with argon. The residue was dissolved in THF and the solution was filtered. The filtrate was analyzed by GPC to determine the $M_{\mathrm{n}}$ and $M_{\mathrm{w}} / M_{\mathrm{n}}$ values of the polymer. The $M_{\mathrm{n}}$ $\left(M_{\mathrm{w}} / M_{\mathrm{n}}\right)$ values of each polymer for $1,2,3$, and 180 min were $11700(1.30), 12900(1.30), 14900(1.30)$, and $18200(1.36)$, respectively.

The polymerizations of $1 \mathrm{a}$ with various amounts of $\mathbf{2}(2.5,6.7$, and $10 \mathrm{~mol} \%)$ were performed for $3 \mathrm{~h}$ in the same manner as above typical procedure; the polymer yields were 94,96 , and $82 \%$, respectively, and the $M_{\mathrm{n}}\left(M_{\mathrm{w}} / M_{\mathrm{n}}\right)$ values were $20700(1.51), 15000(1.34)$, and $7700(1.39)$, respectively.

Reaction mechanism. In order to investigate the reaction mechanism of catalyst-transfer condensation polymerization (Scheme S1), the polymerization of 1a initiated by $5 \mathrm{~mol} \%$ of 2 was carried out in the presence of $5 \mathrm{~mol} \%$ of $\mathbf{6}$ used as a model compound of external Ar(polymer)-Br end. 
If the polymerization proceeds via intermolecular transfer of the palladium catalyst, polymer involving 6 unit is expected to be formed. If no consumption of $\mathbf{6}$ during the polymerization can be found, the intramolecular transfer of the $\operatorname{Pd}(0)$ species from 3a to 4a is supported.

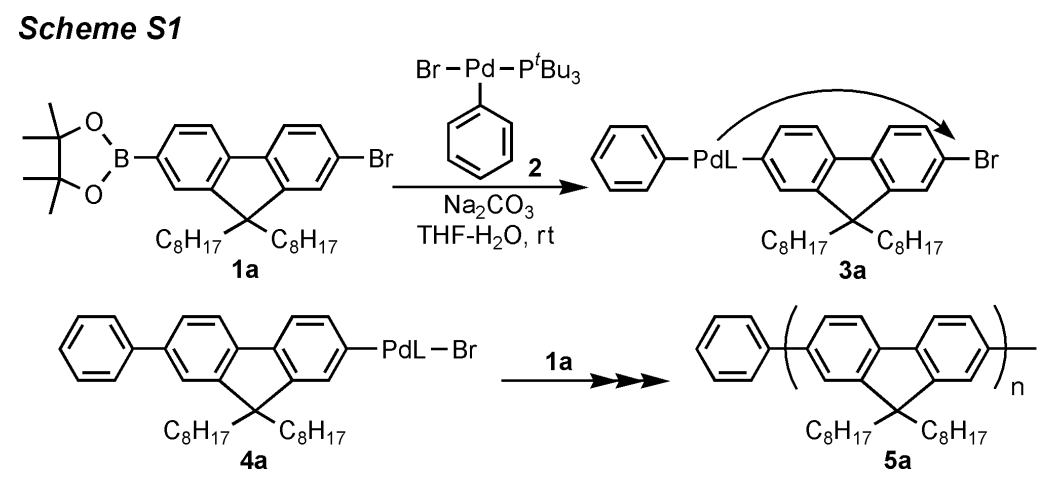

In a two-neck round-bottom flask, $1 \mathrm{a}(50 \mathrm{mg}, 0.084 \mathrm{mmol}), 6$ (2.6 mg, $0.0043 \mathrm{mmol}, 5 \mathrm{~mol} \%)$, and 1-phenyloctane (used as an internal standard for HPLC analysis, $11.5 \mathrm{mg}$ ) were placed and vacuum was applied, which was then cancelled with argon. THF $(4 \mathrm{~mL})$ and $2 \mathrm{~mol} / \mathrm{L}$ aqueous solution of $\mathrm{Na}_{2} \mathrm{CO}_{3}(2.5 \mathrm{~mL})$ were added, and the mixture was stirred at room temperature. The polymerization was initiated by adding a solution of $2(2.5 \mathrm{mg}, 0.0042 \mathrm{mmol}, 5 \mathrm{~mol} \%)$ in THF (1 mL). After $70 \mathrm{~min}$, a sample of the organic phase of the reaction mixture was poured into a mixture of $2 \mathrm{~mol} / \mathrm{L}$ hydrochloric acid and methanol, and the mixture was filtered. HPLC analysis of the filtrate revealed that the conversions of $1 \mathbf{a}$ and $\mathbf{6}$ were $>99 \%$ and $<1 \%$, respectively, determined on the basis of the internal standards. The organic phase was separated and poured into a mixture of $2 \mathrm{~mol} / \mathrm{L}$ hydrochloric acid (2 $\mathrm{mL})$ and methanol $(15 \mathrm{~mL})$ with stirring. The precipitate was collected by filtration and washed with water, methanol, and acetone to remove 6. After drying under reduced pressure overnight, poly $(9,9-$ dioctylfluorene) 5a was obtained (22 mg, $67 \%$ after correction for sampling). $M_{\mathrm{n}}=19200, M_{\mathrm{w}} / M_{\mathrm{n}}=$ 1.34 (GPC). In the ${ }^{1} \mathrm{H}$ NMR spectrum of the obtained polymer (Figure S6a), no peak of the tert-butyl group originated from 6 was detected, although the peak of the tert-butyl group was observed in the spectrum of a mixture of $\mathbf{5 a}$ and $0.5 \mathrm{~mol} \%$ of $\mathbf{6}$ (Figure S6b). No reaction of $\mathbf{6}$ and almost no change of 
$M_{\mathrm{n}}$ and $M_{\mathrm{w}} / M_{\mathrm{n}}$ values support the intramolecular transfer of the $\mathrm{Pd}(0)$ species from 3a to 4a. (Scheme S1).

\section{References}

(1) Zhang, X.; Tian, H.; Liu, Q.; Wang, L.; Geng, Y.; Wang, F. J. Org. Chem. 2006, 71, 4332.

(2) Vahlenkamp, T.; Wegner, G. Macromol. Chem. Phys. 1994, 195, 1933.

(3) Stambuli, J. P.; Incarvito, C. D.; Bühl, M.; Hartwig, J. F. J. Am. Chem. Soc. 2004, 126, 1184. 


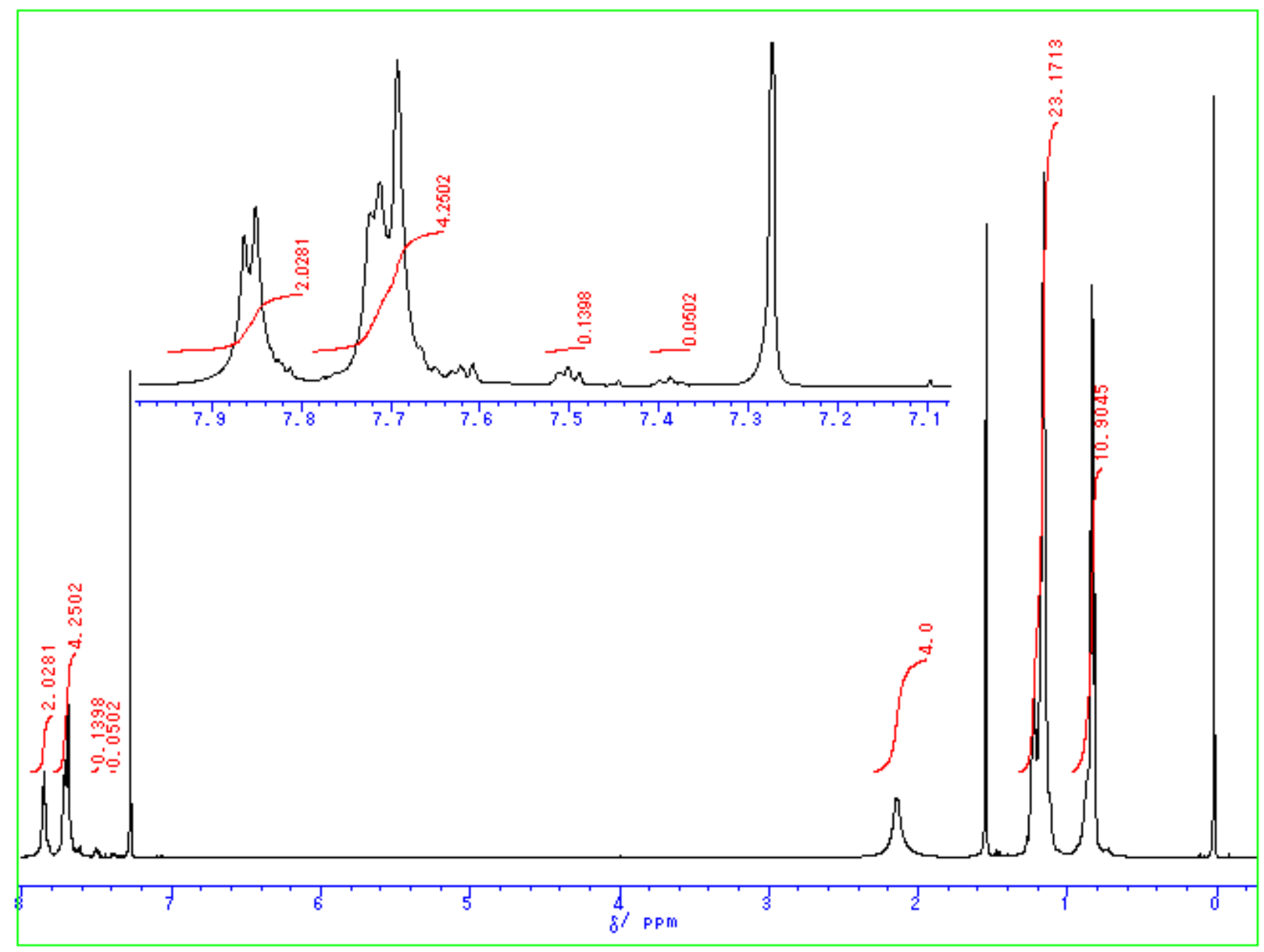

Figure S1. ${ }^{1} \mathrm{H}$ NMR spectrum of the polymer 5a obtained by the polymerization of 1 a with 5 mol \% of 2 in a mixture of THF and $2 \mathrm{~mol} / \mathrm{L}$ aqueous solution of $\mathrm{Na}_{2} \mathrm{CO}_{3}$ at room temperature for $30 \mathrm{~min}$. The small peaks at 7.35-7.55 ppm seem to be due to the phenyl group at the initiator end. 


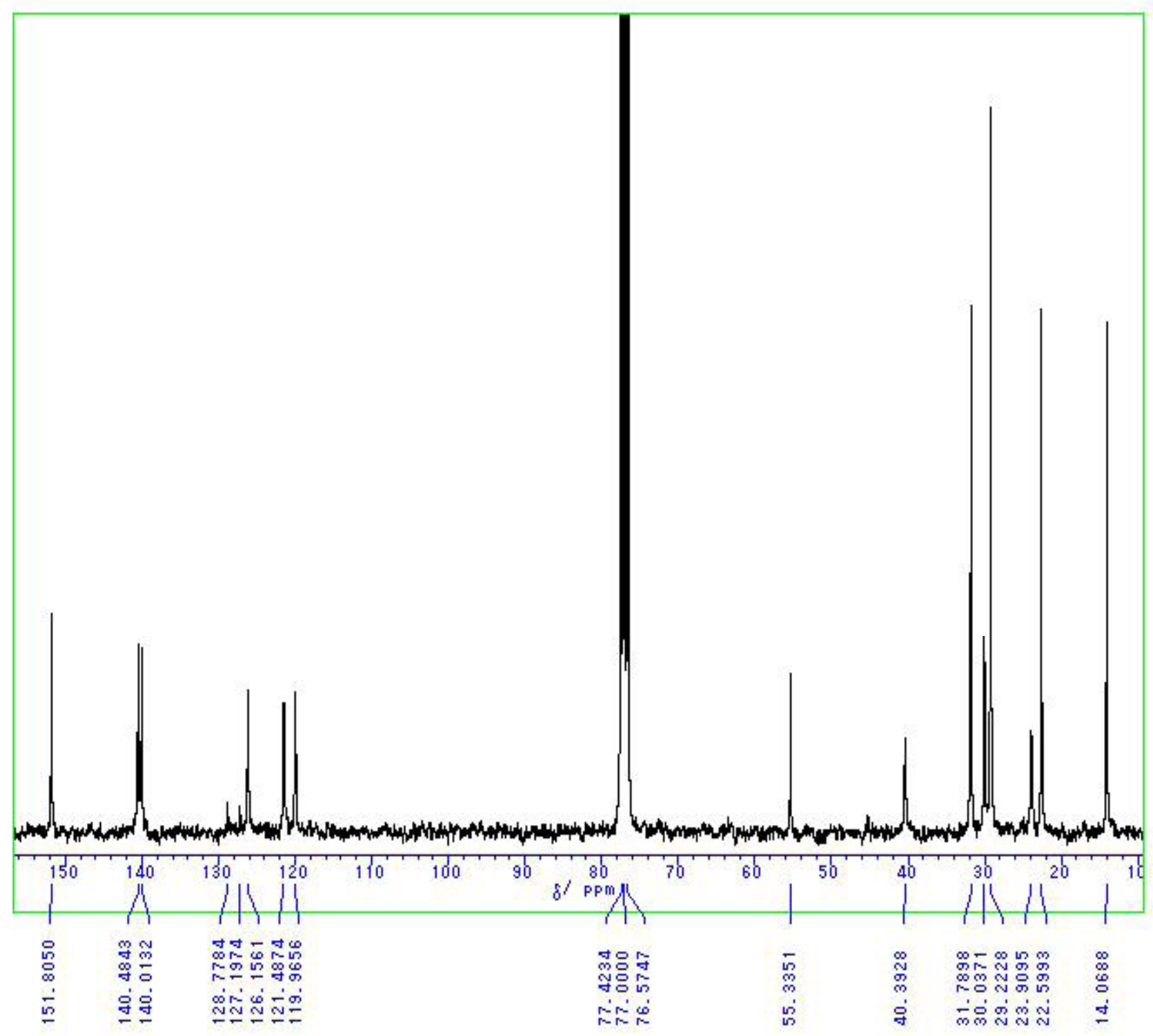

Figure S2. ${ }^{13} \mathrm{C}$ NMR spectrum of the polymer 5a obtained by the polymerization of 1 a with 5 mol \% of 2 in a mixture of THF and $2 \mathrm{~mol} / \mathrm{L}$ aqueous solution of $\mathrm{Na}_{2} \mathrm{CO}_{3}$ at room temperature for $30 \mathrm{~min}$. The small peaks at 127.2 and 128.8 ppm seem to be due to the phenyl group at the initiator end. 


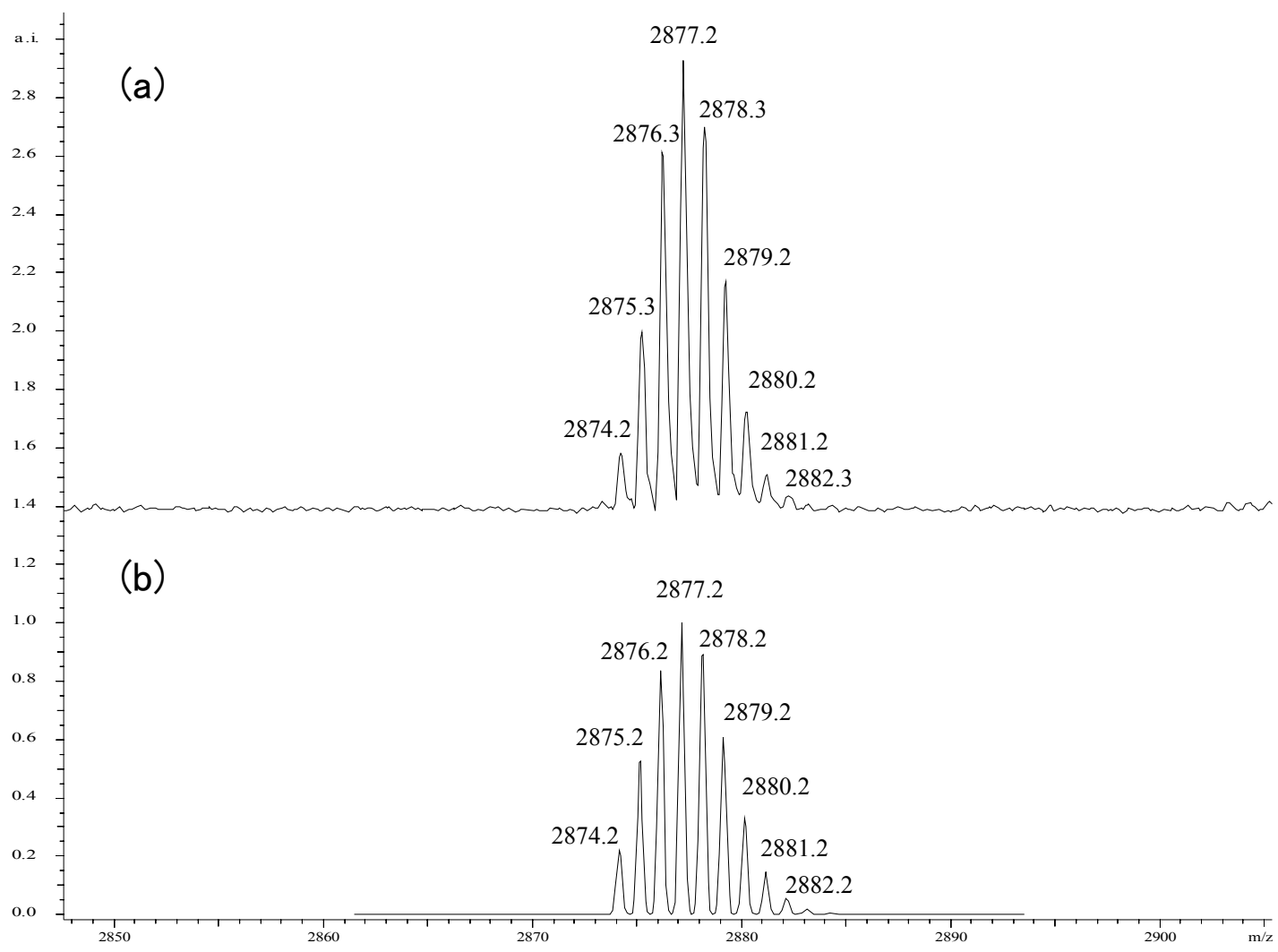

Figure S3. The (a) observed and (b) calculated MALDI-TOF mass spectrum enlarged at the degree of polymerization (n) of 7 of $\mathrm{Ph} / \mathrm{Br}$ ended polymer 5a obtained by the polymerization of 1 a with 5 mol \% of 2 in a mixture of THF and $2 \mathrm{~mol} / \mathrm{L}$ aqueous solution of $\mathrm{Na}_{2} \mathrm{CO}_{3}$ at room temperature for $30 \mathrm{~min}$. 


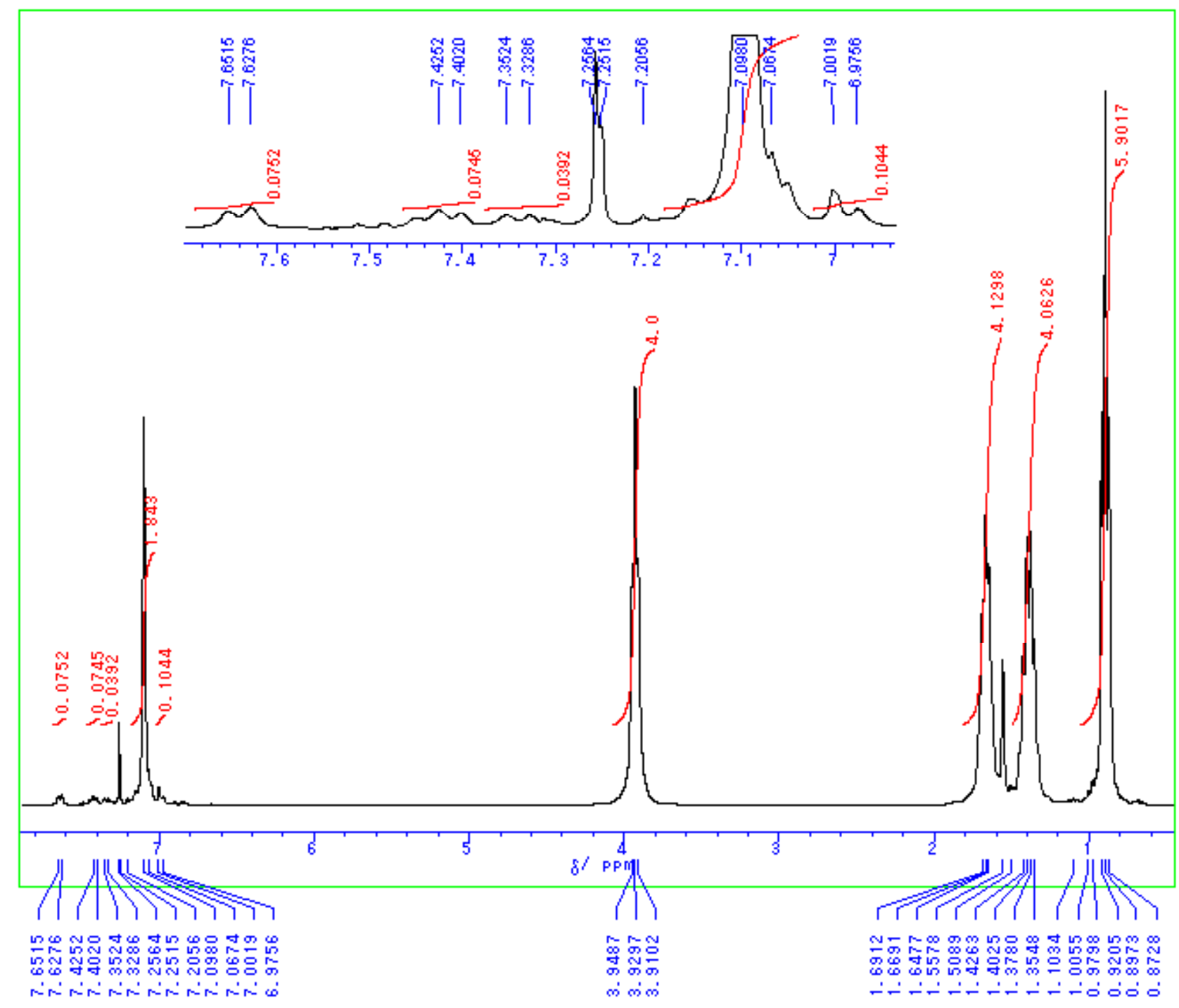

Figure S4. ${ }^{1} \mathrm{H}$ NMR spectrum of the polymer $\mathbf{5 b}$ obtained by the polymerization of $\mathbf{1 b}$ with 5 mol $\%$ of 2 in a mixture of THF and $2 \mathrm{~mol} / \mathrm{L}$ aqueous solution of $\mathrm{Na}_{2} \mathrm{CO}_{3}$ at room temperature for $30 \mathrm{~min}$. The small peaks at $7.33 \mathrm{ppm}(\mathrm{t}), 7.43 \mathrm{ppm}(\mathrm{t})$, and $7.64 \mathrm{ppm}(\mathrm{d})$ seem to be due to the phenyl group at the initiator end. 


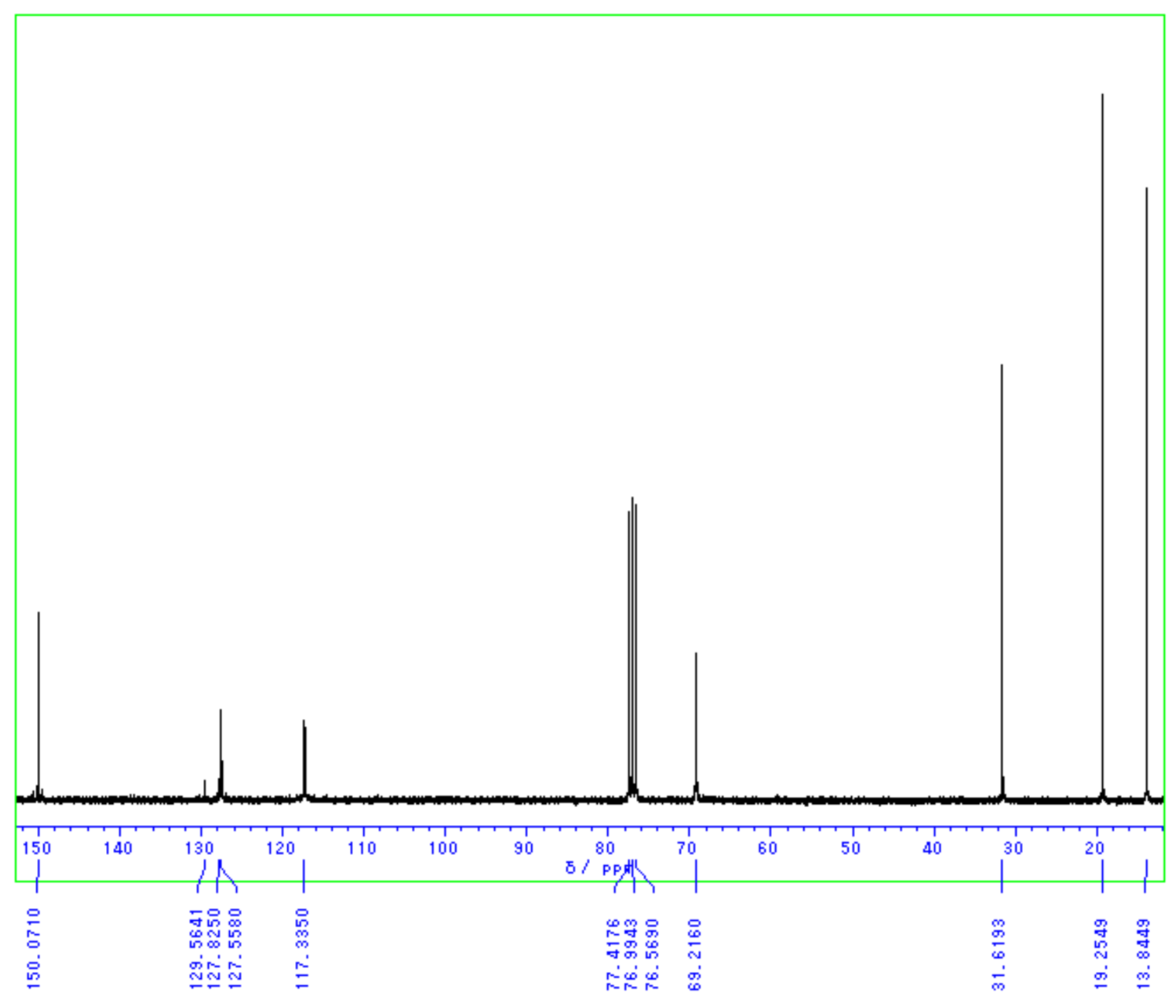

Figure S5. ${ }^{13} \mathrm{C}$ NMR spectrum of the polymer $\mathbf{5 b}$ obtained by the polymerization of $\mathbf{1 b}$ with $5 \mathrm{~mol} \%$ of 2 in a mixture of THF and $2 \mathrm{~mol} / \mathrm{L}$ aqueous solution of $\mathrm{Na}_{2} \mathrm{CO}_{3}$ at room temperature for $30 \mathrm{~min}$. The small peaks at 127.8 and $129.6 \mathrm{ppm}$ seem to be due to the phenyl group at the initiator end. 


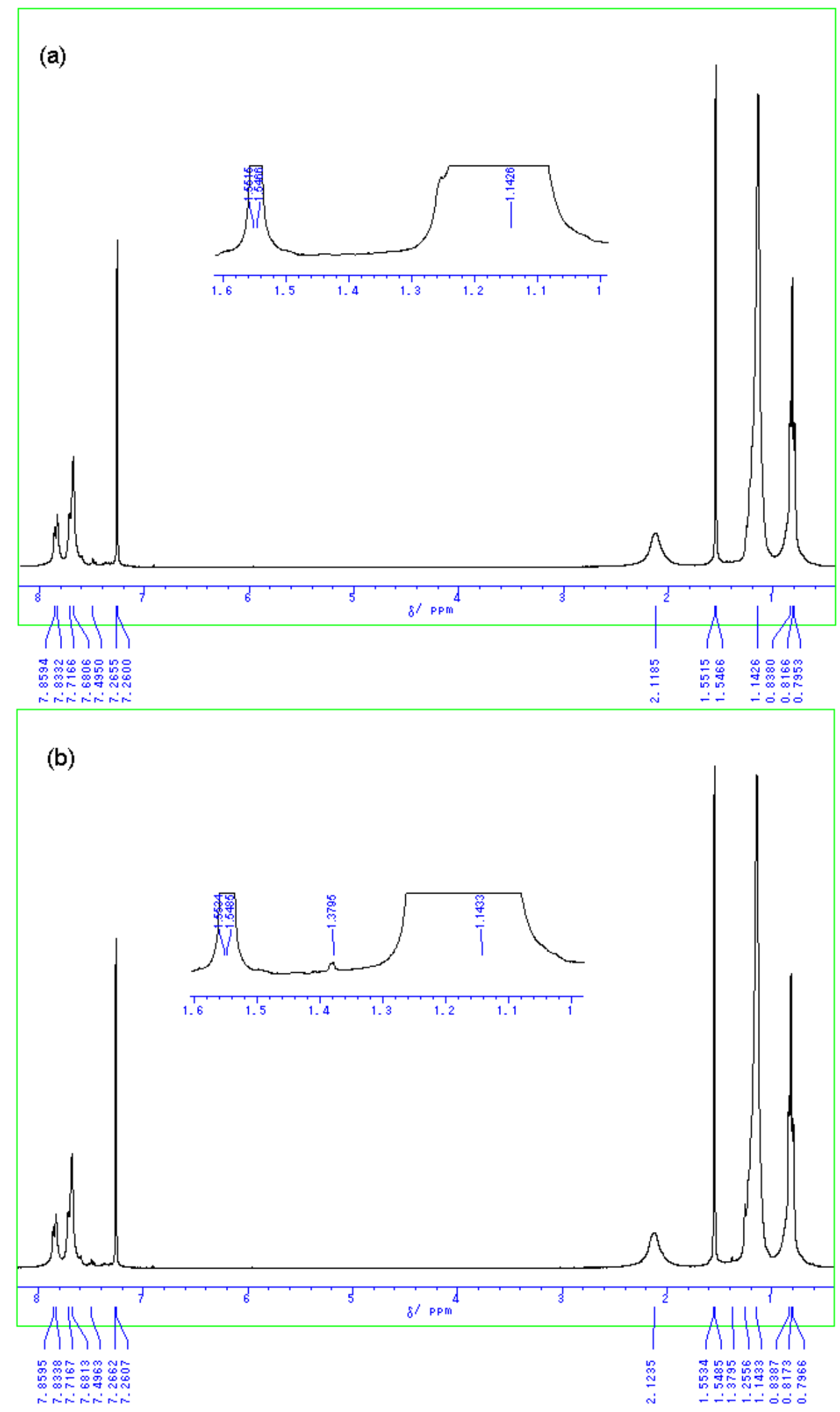

Figure S6. ${ }^{1} \mathrm{H}$ NMR spectra of (a) the polymer 5a obtained by the polymerization of 1 a with 5 mol \% of 2 in the presence of $5 \mathrm{~mol} \%$ of 6 in a mixture of THF and $2 \mathrm{~mol} / \mathrm{L}$ aqueous solution of $\mathrm{Na}_{2} \mathrm{CO}_{3}$ at room temperature for $70 \mathrm{~min}$, and (b) the mixture of the polymer $5 \mathrm{a}$ and $0.5 \mathrm{~mol} \%$ of 6 . 